\title{
Cultural Hegemony and Victimisation of Bedia Women in Central India
}

Usha Rana ${ }^{\dagger}$

\section{Abstract}

Italian philosopher Antonio Gramsci first coined the term "hegemony" and also elaborated on cultural hegemony. It is a common perception that cultural powers and organisations are hegemonic-centred, resulting in a network of invisible powers. Hegemonic power processes are an integral part of daily social and cultural practices that help to perpetuate power relations. The repercussions of hegemony can be seen in various aspects of society, such as caste, class, ethnicity, occupation, gender, tradition, etc. This paper enlightens on the gendered hegemonic cultural practice of prostitution (sex work) as a traditional institution in the Bedia community. The intensive fieldwork in Habla hamlet, a sub-village of Luhari village (village assembly) of the Bedia community in Sagar district in Madhya Pradesh, India, was conducted to reveal the hegemonic practices in the community. Forty people aged between 50 to 60 years have been interviewed for this study. Twenty females and twenty males were selected for data collection, and observations had been made in the hamlet to understand hegemony through social institutions.

Moreover, we have found that the male members are alert to the preservation of the purity and chastity of their wives but compelled their sisters and daughters, with the support of social institutions, to remain unmarried and take up prostitution (sex work). In particular, Bedias' hegemonic traditional cultural behaviour plays an essential role in the continuation of discrimination against Bedia women. Additionally, we explore the mechanism of this hegemonic power through the role of gender, patriarchy, false consciousness, emotions, power of common sense, ideology, and history, which have been responsible for the victimisation of Bedia women for a long time.

Keywords: Bedia women; Hegemony; Patriarchy; Prostitution (Sex Work); Victimisation; Madhya Pradesh, India

\footnotetext{
${ }^{\dagger}$ Assistant Professor, Department of Sociology and Social Work, Dr. Harisingh Gour Central University, Sagar, Madhya Pradesh, India, Email: usharana21@gmail.com

(C) 2020 Rana. This is an Open Access article distributed under the terms of the Creative Commons Attribution License (http://creativecommons.org/licenses/by/2.0), which permits unrestricted use, distribution, and reproduction in any medium, provided the original work is properly cited.
} 


\section{Introduction}

Italian Marxist Antonio Gramsci (1971) writes about the concept of hegemony in his book 'Selections from the Prison Notebooks'. He defined hegemony as the rule and domination generated by cultural or ideological means. It is generally executed by social institutions that have the power to forcefully influence ideas, norms, values, expectations, mindset, sentiments, interpretations, and behaviour of the rest of the society (Gramsci,1971). ${ }^{1}$ Furthermore, he explained the political functions of cultural symbols to give a comprehensive understanding of how some ideas hold up or depolarise existing social structures and social systems of domination and how they are retained through ideological and cultural means. In this process, social institutions play a primary role in influencing the norms, values, ideology, mindset and behaviour of the society. This dominance may be implemented without physical or violent methods, and all social classes or groups see its standards and values as the norm. Though this system claims to benefit all, in reality, it reveals the interests of the ruling class and their strategies to control and dominate the subordinates.

In many cases, the concept of hegemony underlines several social issues, yet serves as an ideological tool to control the subjects. Cultural hegemony works by creating a dominant class, and it influences social and economic structures. Such a power structure differs from governance in the form of a military dictatorship, as it permits the elites, to use authority by peaceful means of ideology and culture (Lears, 1985). Hall (1980) conceptualised hegemony as a power relation structured between "dominance and subordination" (p. 325). It works as a scheme and continues to gain and retain control over the subjects. In addition, studies show that over time, people instinctively construct their symbolic universe to understand and accept the condition of their daily life. Those symbolic universes carry an objective legitimacy over time and generations as they spread from scattered individuals to wider social groups. Public groups serve to validate the views, values, and experiences of leading groups.

This study will discuss the implicit cultural hegemony in the traditional exploitation of women in central India. The continuity of institutional prostitution practice is a problem in states like Madhya Pradesh, Uttar Pradesh and Rajasthan. There is a great debate about the use of the term 'prostitution' and 'sex work'. Although sex work is the phrase largely accepted in academic parlance. For the sake of this research, I use the term 'prostitution'.

Several communities, such as Nat (Azeez, Toolsiram, \& Mishra, 2017) Sansi, Kanjar (TNN, 2016), Bachhada (Singh, 2019), and Bedia (Rana et al. 2020) have been engaged in this occupation of prostitution for many generations. Besides, this process has resulted in creating a vicious chain of child trafficking and the spread of many sexually transmitted diseases. However, the welfare states, working for the betterment of individuals, have enacted several laws for social reform. Many nongovernmental organisations have also been paying attention to it. Yet, the women of the Bedia community are still dominated by the traditional and patriarchal social practice of prostitution. They are forbidden to lead an ordinary life, get an education or a career or a family. Social institutions force them into prostitution which is backed by norms, beliefs, emotions, values, and ethics. Since childhood, girls are trained to become prostitutes and be responsible for earning money for the family. The Bedia community is financially dependent on its prostitute women in a major way. However, the male members of the Bedia community are not expected to take up family responsibilities. The community has never compelled males to be accountable for the upkeep of their families. Rather, they work as

\footnotetext{
${ }^{1}$ Antonio Gramsci (1891-1937) was an Italian Marxist philosopher and Communist. He contended Marx's theory of Economic Determinism by neo-Marxism.
} 
pimps and agents for their sisters and daughters engaged in prostitution. Moreover, they prefer to marry virgin girls from outside their community. Such duality in the same community raises several questions. However, it should be noted that not all deprived communities have been surviving on such socially deviant practices. The hegemonic practices in the Bedia community will be discussed in detail in this study.

In the remainder of this study, the next section presents the theoretical insight into cultural hegemony and women's victimisation. This is followed by a brief overview of violence through prostitution, after which the research methodology and an explanation of the socioeconomic profiles of the respondents are presented. The following sections concern the analysis of the fieldwork, discussion and concluding remarks.

\section{Theoretical Insight}

Hegemony can be seen in most aspects of ordinary life. In patriarchal societies, women have been vulnerable for a long time. When a woman is born in a socially deviant environment, she often becomes a victim through its cultural practices. Many communities in central India train their girls to be prostitutes. Since prostitution remains morally undesirable, we cannot ignore the continuity of prostitution in such communities. Previous researches on prostitution have claimed that prostitution is one of the oldest professions in the world (Lerner, 1986; Ericsson, 1980; Brundage, 1976). Several factors are cited to be responsible for prostitution, namely, social (Chakraborty, 1963; Sharma, 2007), religious (Tarachand, 1991; Chakravarti, 2006; Shingal, 2015), economic (Jeffries, 1997), and biological (Devis, 1937). Prostitution is controlled by extreme views and values that oppress women. Women suffer not only physically in the profession in which they have been forced to enter, but also psychologically due to the stigma attached to the profession by society. This is precisely an

\footnotetext{
2 Patriarchy is a social structure where male dominates the female and legitimises it within the society through superiority on all rights, authority and power.
}

organised system or practice, which assists in continuing the hegemonic beliefs that oppress women in various aspects of their lives. Hence, sexual exploitation of women seems to be a privilege of the sovereign class, a precedence that allows it to maintain its socio-cultural and economic hegemony. Foucault's study shows that local hegemonic power is a continuous process of "produc[tion of] knowledge" in favor of power (Foucault, 1979 p. 27). Bourdieu mentioned that hegemonic power is a process of "identity formation" (Bourdieu, 1991, p. 302). People formulate and consolidate their commonly shared sense of social reality according to structure systems and format their meaning of a particular point through the power processes. Certain conceptions of reality are organised into everyday practices, while society organises other possible conceptions (Mumby \& Stohl, 1991).

In the global context, prostitution is condemned as a violation of human rights, an institution that dispenses death and disease to women (Raymond, 2004), and a notably roguish institution of the inequality of the sexes (Farley, 2004). Farley and Kelly elucidated prostitution as rape, battering and sexual harassment of women (Farley \& Kelly, 2000). In tying female prostitution to capitalism and patriarchy. ${ }^{2}$ Marxist views attempt to link it to particular historical forces rather than biological or natural. Besides, Gayle Rubin has tried to provide a purely social and historical analysis of female prostitution by applying some insights into structuralized anthropology. She opines that economic prostitution originates from the unequal position of men and women within the mode of reproduction (Gayle, 1975). To treat a woman as a sex object is to automatically treat her as less than fully human. Moreover, some researchers make a distinction between forced and voluntary prostitution, but it is fairly unacceptable because some coercion and domination are always and unfailingly involved with it. Victims of voluntary prostitution too 
have been found to suffer physical and physiological violence.

\section{Violence through Sex Work/Prostitution}

Studies on sex work in the global context reveal the amount of violence experienced by sex workers (Kurtz, Surratt, Inciardi, \& Kiley, 2004; Perkins, 1991; Perkins and Lovejoy, 1996). A study of five countries reported that almost $80 \%$ of the respondents had been physically hurt, and $60 \%$ of the women had been sexually assaulted by their clients, pimps, and traffickers (Raymond, 2004). Raphael and Shapiro (2002, 2004) reported high figures for Chicago: $86 \%$ of street sex workers were slapped, $70 \%$ had been punched, $79 \%$ had been threatened with a weapon, and $64 \%$ had been forced for sex. Similarly, other figures of violence have been found from Thailand, Turkey, South Africa and Zambia (Farley \& Barkan, 1998). The study of Farley and Barkan (1998) on 130 street-based prostitutes in San Francisco found that $68 \%$ had been raped and $82 \%$ had been physically assaulted while working. Contemporary research focuses on violence against female sex workers as victims rather than offenders (Monto, 2004; Monto et al., 2005). The studies mentioned above focus on the level of violation, harm and trauma caused by prostitution against women. In a study of 294 prostitutes in Miami, for instance, almost all of them preferred the terms "sex worker" and "working woman" and referred to themselves as such (Kurtz et al., 2004). Nevertheless, prostitution is an institution of victimisation of women.

Thus, the traditional practice of a particular profession is supported by social institutions and discourse. It is strongly asserted by the ruling class that the economic and social conditions of the society are inescapable. Arguably, these conditions are being built by people's inherent interest in a unique system. Gramsci argued that dominant groups attain consent from society by the spread of ideologies, beliefs, assumptions, and values through social institutions such as families, kinship, and religion, among others (Gramsci, 1971). The social institutions position people through the values, norms, and beliefs of the ruling class. Accordingly, the group that controls these entities controls the rest of the society (Cole, 2020).

Gramsci (1971) confirmed the power of ideology to reproduce the social structure through institutions. He portrayed the intellectuals of society as the detached observers of societal life. However, they remain privileged by their upper status in the community and enjoy honour as they work as the deputies of the dominated class to motivate ordinary people to accept established rules.

Hegemony can be seen as inherent in all kinds of social systems from ancient societies to the modern. Ordinary people of the Bedia society accept such a system as a normal process as the Bedia community has been continuing prostitution as a traditional occupation. In fact, the male members of that society work as pimps for their women. It is clear that the patriarchal system has always discriminated between the genders. The Bedia male leads a normal life, has a monogamous marriage with a virgin from outside the community and takes a hefty dowry. Despite being in the same social system, the wives are forbidden to participate in the traditional occupation while all kinds of restrictions are forced on the sisters and daughters. They are not allowed to maintain a stable relationship within or outside the community and are trained to become prostitutes. This paper will deal with the primary data of the Bedia community.

\section{Research Methodology}

In this paper, the analysis of hegemony is built on a theoretical understanding of hegemony and qualitative empirical data collected from interviews (from November 2018 to September 2019). The interview is the direct method of primary data collection. This study is based on data collected from interviews conducted in the local language (Bundelkhandi, a sublanguage of Hindi) of Madhya Pradesh. The respondents' statements have been translated into English by the author.

Audio-recorded interviews were conducted. Selected narrations from respondents in their local language form the basis for understanding the practices. Data has been collected from 
Habla hamlet, a sub-village of Luhari (panchayat) village of Sagar district of Madhya Pradesh, India. The Bedia population inhabits all the area. As per the document of local governance, the number of people in the hamlet is 615 . In this study, we shall discuss the cultural hegemony underlying the institutional prostitution in the Bedia community. Such prostitution is socially accepted as an ordinary way of life. I interviewed 40 people from the village. All interviewees were between $50-60$ years of age. Twenty females and twenty males were selected for data collection. During the field visit, observations had been made in the hamlet to understand the hegemonic cultural practices of the community. Secondary data has been used to understand a particular concept in the context of the Bedia community. Scholarly articles were drawn from primary texts and media reports in national newspapers.

\section{Socio-Economic Profile of the Respondents}

All the respondents, twenty males and twenty females, belonged to homogeneous social background, being born and nurtured in the same environment; they belong to the Scheduled Caste category (SC). ${ }^{3}$ It is to be noted that the Constitution of India recognises SC as one of the marginalised or depressed group. They were found to accept prostitution as an acknowledged means of survival. All respondents were uneducated and lived in a rural area. Their community has separate norms and values for social institutions like family, marriage, and kinship when compared to other societies of north India. Their family constitutes of the Bedia male, his wife (belonging to a nonBedia clan from outside the community) and children. The biological fathers do not recognise their children because they are the illegitimate children of women engaged in prostitution. The women of the Bedia community have been compelled to enter prostitution for generation after generation. The economic profile of respondents is not much varied. However, a disparity can be seen in the economic profile of

\footnotetext{
${ }^{3}$ Scheduled Caste Welfare - List of Scheduled Castes, Ministry of Social Justice and Empowerment, Government of
}

families in which the number of female members working as prostitutes is more, especially if they are young. Such families have an average income of ten thousand to fifteen thousand per month. Women working in urban areas earn more. One additional point related to earning is that prostitutes considered beautiful or skilled in Rai folk dance are more in demand and hence, earn better.

\section{Analysis}

Primary and secondary data has been used in a theoretical manner to understand the easy acceptance of prostitution as a way of life in the Bedia community. Hegemony can be recognised in all societies in various aspects of daily life where one person or group dominates the other. The continuity of such practices subjects the victim to exploitation on many levels. In this study, we shall focus on the Bedia women who are involved in prostitution. The alarming point to be raised is that if prostitution is the only means of survival for the community, then why do the Bedia men marry virgins from outside the community while forcing the women within the community into prostitution. On the other hand, Bedia women have never strongly raised their voice against such practice. The following discussion is based on theoretical and empirical evidence from the field area. The discussion will be based on the context of gender; the ways in which the Bedia males dominate over the females. They use the power of history to justify themselves. Collectively the community misleads women by making them responsible for all kinds of family duties. However, the power of common sense gives spontaneous consent for institutional prostitution. The ideology of the community about prostitution makes mutualism among the community. Emotions of primary institutions provide power to the community to continue prostitution as a tradition.

\section{Gender Context}

Discrimination on the basis of gender is a social reality. Women are fighting for their rights in

India.https://web.archive.org/web/20120913050030/htt $\mathrm{p}: / /$ socialjustice.nic.in/sclist.php 
social, economic and political arenas in all communities (Dunn, 1993; Banerjee, 2014; Bhattacharyya, 2014; 2015; 2017; Verniers and Vala, 2018). In this study, cultural hegemony is implicit in the traditional exploitation of women because social structures seem to frame double standards in the context of duties, rights, behaviours for men and women. The Bedia community has double standards for the male and the female (Rana et al. 2020). While the men enjoy all sorts of freedom, marry virgins outside the Bedia community and live as parasites surviving on the money earned by the women through forced prostitution, the women are victimised throughout their lives and are compelled to take up all kinds of family liabilities.

\section{History and Power}

Foucault's (1980) theorisation on body and sexuality represents sexuality not as a natural, fixed fact but as a set of effects produced by bodies, behaviours and social relations by a certain deployment derived from a complex political technology. Foucault cites a social strategy of possession of the body in the social and cultural context. In this way, the history of cultural practices creates a system which can control the natives of that society when its members begin to trust the system to the degree that they are unable to think beyond the dictates of culture. For instance, the Bedia community controls the woman's body for livelihood; the sisters and daughters of its male members are not permitted to get married. Interviewed Bedia people states:

Our ancestors started it; we are just following our tradition, and there is nothing wrong in it. As other castes like Brahmins, ${ }^{4}$ Businessmen are doing their work; we are also doing our work.

\section{Misleading}

Friedrich Engels used the term 'false consciousness' demonstrating the exploitation by the bourgeoisie on the proletariats (Eagleton, 1991). Similarly, the male members of the Bedia community have been misleading Bedia women on the basis of 'culture' and 'tradition'. Prostitution being their usual occupation, women enter into it without rebellion. On the other side, male members enjoy a normal family life. When the correspondent asked the members to try to root out this tradition from their community, they answered in their local language:

It is our fate that we were born in Bedia community. That's why we have to follow the traditions of this community. If God did not want this from us, then our birth would also have occurred somewhere else.

Hence, it may be said that in the Bedia community, traditional headship has created a power structure which has resulted in controlling the means of production in support of the male.

\section{Power of Common Sense}

Gramsci (1971) has opined that when the majority of the population accepts the functioning of the society, it means that spontaneous consent has been given by the masses to the dominant groups to impose general directions on social and economic life. However, prostitution had been accepted as a source of livelihood in the Bedia community due to unfavourable conditions in the colonial period (Gathia, 1999). However, the Bedia community has structured its mechanism in the following manner. There are two categories of women to be found in a single family- one involved in prostitution and the other fulfilling the demands of a chaste wife. The general consent of the whole community in this matter is quite surprising. However, there are certain restrictions maintained, like no male shall marry in the community, etc. During the fieldwork, one woman shared how a relationship between two adolescents in the community became the subject of a big quarrel and disagreement.

\footnotetext{
${ }^{4}$ Within the caste institution of India, the Brahmin caste belongs to the highest ladder in the caste system. But in this study, it refers to the priests of the temples.
} 


\section{Ideology}

Ideology is an arrangement of ideas expressed through communication; and consciousness is the essence or totality of attitudes, opinions, and sensitivities held by individuals or groups. Hegemony is the process through which dominant ideology is transmitted through consciousness, and social power is exercised (Lull, 1995). Ideas generated through social systems invariably influence each other. The Bedia community's traditional ideology works in the social system by its total control of the consciousness of its members. It tacitly supports deviant practices such as prostitution as normal and acceptable, and this collective ideology gives support to the continuity of institutional prostitution. Even Bedia women who are being exploited by this practice are not found to raise their voice against it. It has unreservedly become a vital part of the system.

\section{Mutualism}

People of the Bedia community must depend upon each other for continuation of the practice of prostitution. Since all have a common interest, they work collectively. Therefore, the administration fails to make an impact or have command over the situation. Many policies and laws have been repeatedly adopted by the State Government of Madhya Pradesh against institutional prostitution, but it has so far been unable to root out the problem. However, in recent times, many cases have been reported where Bedia girls and women have been rescued from metro cities like Delhi and Mumbai, and some parts of West Bengal (Mohan, 2017). They were handed over to their respective families, but due to the exercise of institutional prostitution, they were again compelled to go into the same profession. Hence, in a community, mutualism works for the dominant group's benefit.

\section{Emotions and Power}

Bedia girls are trained and socially conditioned to become prostitutes. Having a girl child is even considered to be good luck in a Bedia family. Bedia girls are made to learn all kinds of skills from their aunts and elder sisters who are already involved in prostitution. Bedia families habitually manipulate their girl child using physical and psychological pressure (Vauquline, 2015). As children, these girls lack critical consciousness and hence emotions are strategically made to play a major role as the abstract means of domination and subordination.

\section{Discussion}

Senior citizens of the Bedia community claim that the girls are free to decide whether they want to enter into prostitution or not. Yet, there is no significant evidence or instance of Bedia girls getting married in the village. As a matter of fact, Bedia women are not themselves aware of their own exploitation in their community. They stated, "People identify us as bad women. Some clients visit us regularly for some time, but we do not have the right to love anyone. Clients often misbehave with us; we are neither socially nor emotionally secure". Bedia women usually work in this profession between the ages of 15-35. However, they are not financially secure even after retirement. Most of them do not want the same occupation for the next generation. Still, due to lack of opportunity and the hegemonic tradition of institutional prostitution, the next generation invariably gets engaged in it. However, some hope can be found in a few other states where the Bedia community resides. It can be safely said that some outside intervention has played a significant role in eradicating this vicious problem (Agha, 2015).

\section{Conclusion}

There are several leading factors such as poverty, illiteracy, unemployment and lack of awareness behind women's victimisation in the Bedia community. As Antonio Gramsci conceptualised hegemony, social institutions in the Bedia community too play a key role in the lives of female children from the very beginning in controlling their bodies as commodities. They use instances from community history in the context of prostitution, which serves to mislead the community members. They attempt to establish a collective consent from the community that prostitution is as legitimate an occupation as others. Such an ideology creates 
mutualism in Bedias and has resulted in a vicious chain for woman's exploitation as well as a trap for child trafficking and the spread of other sexually transmitted diseases. The problem may sound local, but its impact can be seen globally in the form of women and child trafficking.

\section{References}

Agha, E. (2015, December 27). From dance bars to school: Bedia girls on reforms path. The Times of India. Retrieved from https://timesofindia.indiatimes.com/city/agra/F rom-dance-bars-to- school-Bediagirls-onreforms-path/articleshow/50338469.cms.

Azeez, E. P. A., Toolsiram, R., \& Mishra A. (2017). Rajnats of Rajasthan and the Sex Work: An Ethnographic Study, Contemporary Voice of Dalit, 9(1), 37-47. DOI:

\section{$10.1177 / 2455328 \times 17689862$.}

Banerjee, R. P. (2014). Dowry in 21st-Century India: The Sociocultural Face of Exploitation, Trauma. Violence, \& Abuse, 15(1), 34-40. DOI: $10.1177 / 1524838013496334$.

Bhattacharyya, R. (2014). Life and times of unborn Kamla. Space and Culture, India, 2(2), 57-58. DOI: 10.20896/saci.v2i2.89.

Bhattacharyya, R. (2015). Understanding the Spatialities of Sexual Assault Against Indian Women in India. Gender, Place and Culture, 22(9), 1340-1356. DOI: 10.1080/0966369X.2014.969684.

Bhattacharyya, R. (2017). What gender is, what gender does. Gender, Place \& Culture, 25(3), 467-469. DOI:

10.1080/0966369X.2017.1338432.

Brundage, J. A. (1976). Prostitution in the Medieval Canon Law. Journal of Women in Culture and Society, 1(4), 825-845. Retrieved Dec. 21, 2019, from www.jstor.org/stable/3173236.

Bourdieu, P. (1991). Language and Symbolic Power. Polity Press, Cambridge.

Chakraborty, U. (1963). Condition of Bengali women: Around the second half of the 19th century. Published by Author, Calcutta.
Chakravarti, U. (2006). Everyday Lives, Everyday Histories: Beyond the Kings and Brahmanas of 'Ancient' India. Tulika Books, New Delhi.

Cole, N. L. (2020). What Is Cultural Hegemony. ThoughtCo. Retrieved from https://www.thoughtco.com/culturalhegemony-3026121.

Dunn, D. (1993). Gender inequality in education and employment in the scheduled castes and tribes of India. Population Research and Policy Review, 12(1), 53-70. DOI:

10.1007/BF01074509.

Devis, K. (1937). The Sociology of Prostitution. American Sociological Review, 2(5), 744-755.

Retrieved Jan. 21, 2020, from

www.jstor.org/stable/2083827.

Eagleton, T. (1991). Ideology, Verso, New York.

Ericsson, L. O. (1980). Charges against

Prostitution: An Attempt at a Philosophical Assessment. Ethics, 90(3), 335-366. Retrieved Jan. 15, 2020, from www.jstor.org/stable/2380575.

Farley, M. \& Barkan, H. (1998). Prostitution, Violence, and Post-Traumatic Stress Disorder. Women and Health, 27(3), 37-48. DOI: 10.1300/J013v27n03_03.

Farley, M. \& Kelly, V. (2000) Prostitution: A Critical Review of the Medical and Social Sciences Literature. Women and Criminal Justice, 11(4), 29-64. DOI:

10.1300/J012v11n04_04.

Farley, M. (2004). Bad for the body, bad for the heart: Prostitution harms women even if legalized or decriminalized. Violence Against Women, 10(10), 1087-1125. DOI:

10.1177/1077801204268607.

Foucault, M. (1979). Discipline and punish: The birth of the prison. Vintage Books, New York,

Foucault, M. (1980). The history of sexuality: An introduction (vol. 1). Vintage Books, New York.

Gathia, J. (1999). Child prostitution in India. Concept Publishers, New Delhi.

Gayle, R. (1975). The Traffic in Women: Notes on the "Political Economy" of Sex. In Reiter, R. 
R. (Ed.), Toward an Anthropology of Women (pp. 157-210). Monthly Review Press.

Gramsci, A. (1971). Selections from the Prison Notebooks (translated and edited by Quintin Hoare and Geoffrey Nowell Smith). International Publishers, New York.

Hall, S. (1980). Race, articulation and societies structured in dominance. In Unesco, Sociological Theories: Race and Colonialism (pp. 305-345). Unesco, Paris.

Jeffries, S. (1997). The Idea of Prostitution. Spinifex Press, North Melbourne.

Kurtz, S., Surratt, H., Inciardi, I., \& Kiley, M. (2004). Sex work and date violence. Violence Against Women, 10(4), 357-385. DOI: 10.1177/1077801204263199.

Lears, T. J. J. (1985). The Concept of Cultural Hegemony: Problems and Possibilities. The American Historical Review, 90(3), 567-593. DOI: $10.2307 / 1860957$.

Lerner, G. (1986). The Origin of Prostitution in Ancient Mesopotamia. Journal of Women in Culture and Society, 11(2), 236-254. Retrieved Dec. 25, 2019, from www.jstor.org/stable/3174047.

Lull, J. (1995). Media, Communication, and Culture: A Global Approach. Columbia University Press, New York.

Mohan, S. (2017, July 28). Childhood for sale. The Hindu Business Line. Retrieved from https://www.thehindubusinessline.com/blink/k now/childhood-forsale/article9790915.ece.

Monto, M. A. (2004). Female prostitution, customers, and violence. Violence Against Women, 10(2), 160-168. DOI: $10.1177 / 1077801203260948$.

Monto, M. A., \& McRee, N. (2005). A Comparison of the Male Customers of Female Street Prostitutes with National Samples of Men. International Journal of Offender Therapy and Comparative Criminology, 49(5), 505-529. DOI: $10.1177 / 0306624 \times 04272975$.

Mumby, D.K. \& Stohl, C. (1991). Power and Discourse in Organization Studies: Absence and the Dialectic of Control. Discourse and Society.
2(3), 313-332. DOI:

10.1177/0957926591002003004.

Perkins, R. (1991). Working girls: prostitutes, their life and social control. Natl Gallery of Australia, Parkes.

Perkins, R., \& Lovejoy, F. (1996). Healthy and unhealthy life styles of female brothel workers and call girls in Sydney. Australian and New Zealand Journal of Public Health, 20(5), 512516. DOI: 10.1111/j.1467-842x.1996.tb01631.x.

Rana, U., Sharma, D. \& Ghosh, D. (2020). Prostitution in northern Central India: an ethnographical study of Bedia community. International Journal of Anthropology and Ethnology, 4(1), 1-16. DOI: 10.1186/s41257-020-0027-5.

Raphael, J., \& Shapiro, D. (2002). Sisters speak out: The lives and needs of prostituted women in Chicago. Center for Impact Research. https://www.issuelab.org/resources/351/351.p df.

Raphael, J., \& Shapiro, D. (2004). Violence in indoor and outdoor prostitution venues. Violence Against Women, 10(2), 126-139. DOI: $10.1177 / 1077801203260529$.

Raymond, J. (2004). Prostitution on demand: Legalizing the buyers as sexual consumers. Violence Against Women, 10(10), 1156-1186. DOI: $10.1177 / 1077801204268609$.

Sharma, K. (2007). The Social World of Prostitutes and Devadasis: A Study of the Social Structure and Its Politics in Early Modern India. Journal of International Women's Studies, 9(1), 297-310. Retrieved Jan. 10, 2020, from http://vc.bridgew.edu/jiws/vol9/iss1/17.

Shingal, A. (2015). The Devadasi system: Temple Prostitution in India, UCLA Women's Law Journal, 22(1), 107-123. Retrieved Jan. 20, 2020, from

https://escholarship.org/uc/item/37z853br.

Singh, R. (2019, January 06). Madhya Pradesh tops in missing kids' count. The Times of India. Retrieved from https://timesofindia.indiatimes.com/city/bhopa I/mp-tops-in-missingkidsco 
unt/articleshow/67401655.cms.

Tarachand, K.C. (1991). Devadasi custom: Rural social structure and flesh markets. Reliance Publishing House, New Delhi.

TNN. (2016, December 06). 7 including minor girl rescued from prostitution. The Times of India. Retrieved from http://timesofindia.indiatimes.com/articleshow /55714052.cms?utm_sourc e=contentofinterest\&utm_medium=text\&utm_ campaign $=$ cppst.

Vauquline, P. (2015). Socialisation Process, Power Relations and Domestic Violence: Marginal Voices of Assamese Women. Space and Culture, India, 3(2), 54-71. DOI: 10.20896/saci.v3i2.155.

Verniers, C. \& Vala, J. (2018). Justifying gender discrimination in the workplace: The mediating role of motherhood myths. PLOS ONE, 13(1), 123. DOI: 10.1371/journal.pone.0190657. 